\title{
The Altered Cast Technique: A Case Report
}

Singh $\mathrm{SK}^{1}$, Singh RK${ }^{2}$, Suwal $\mathrm{P}^{3}$, Parjuli $\mathrm{PK}^{4}$, Limbu $\mathrm{IK}^{5}$, Basnet $\mathrm{BB}^{6}$

${ }^{1}$ PG Resident, Department of Prosthodontics, College of Dental Surgery-BPKIHS, Dharan, Nepal

${ }^{2,3}$ Professor, Department of Prosthodontics, College of Dental Surgery-BPKIHS, Dharan, Nepal

${ }^{4}$ Associate Professor, Department of Prosthodontics, College of Dental Surgery-BPKIHS, Dharan, Nepal

${ }^{5}$ Assistant Professor, Department of Prosthodontics, College of Dental Surgery-BPKIHS, Dharan, Nepal

\begin{abstract}
The altered cast impression technique is commonly used for the mandibular distal extension partially edentulous arches. The technique is relatively simple and improves the residual ridge to dentition relationship of the prosthesis. Due to the displaceability of the mucosa, free end saddles get displaced under occlusal load.

A 45-year-female patient reported to the Department Of Prosthodontics and Crown-Bridge, College of Dental Surgery, B.P. Koirala Institute of Health Sciences, Nepal with a chief complaint of missing bilateral lower posterior teeth. Clinical examination revealed missing teeth w.r.t 36, 37, 45, 46 and 47. Treatment plan was made to rehabilitate the patient with removable partial denture using functional impression along with the altered cast technique.

Altered cast technique is the best alternative technique in case of distal extension cases because better tissue adaptability, proper extension of denture base, equal stress distribution, better support and stability can be achieved. Finally, increased patient comfort and function is obtained.
\end{abstract}

Key words: Altered cast technique; Distal extension; Free end saddles.

\section{Introduction}

$\mathrm{T}$ he primary objective of prosthesis should be the preservation of oral structure. ${ }^{1}$ Kennedy's class I and II removable partial denture are not entirely tooth supported so successful oral rehabilitation becomes more challenging in these cases. ${ }^{2}$ Multiple treatment options are available for distal extension cases, which include removable partial dentures, clasp retained removable partial dentures and implant supported fixed prosthesis. Insufficient amount of bone, local or systemic factors and low economics preclude implant placement. ${ }^{3,4}$ Removable partial dentures derive support both

\section{*Corresponding Author}

Dr. Somika Kumari Singh, PG Resident

Department of Prosthodontics, College of Dental Surgery-BPKIHS, Dharan, Nepal

E-mail:drsomika321@gmail.com from soft and hard tissues in which terminal abutment acts as fulcrum. ${ }^{5}$ Fabrication of distal extension partial dentures most commonly use alter cast impression technique because it equally distributes stress between soft and hard tissues, reduce the load on the abutment teeth, decrease food impaction and preserve the residual ridges, leading to increased patient satisfaction. ${ }^{6,7}$ This case report describes an easy and quick method of altered cast technique for construction of removable partial dentures.

\section{Case report}

A 45-year-old female patient reported to the Department of Prosthodontics and CrownBridge, College of Dental Surgery, B.P. Koirala Institute of Health Sciences, Nepal with a chief complaint of missing lower posterior teeth (Fig.1). Clinical examination revealed missing 36, 37, 45, 46, and 47. All the treatment modalities were discussed with the patient 
including implant supported prosthesis. Due to cost and time constraint, patient rejected implant supported fixed prosthesis and opted for cast removable partial denture. So, replacement of missing teeth by removable cast partial denture using altered cast impression technique was planned, because this technique allows the ridge to be recorded in functional form due to which, when prosthesis is seated, it simultaneously derives support from the tooth and the denture base.

Diagnostic impressions were made with irreversible hydrocolloid impression material (Algitex, Dental Products of India) and poured with Type II dental stone (Kalastone, KalabhaiPvt. Ltd.). The study casts were placed on a surveyor for examination and design of the cast metal framework. Mouth preparation was done (Fig. 2A) and final impression were made with addition silicone (Polyvinyl siloxane,Coltene) and light bodied elastomer (Reprosil VPS Impression Material, Dentsply) impression material (Fig. 2B) to record details of the tooth preparation. Impression was removed from mouth, rinsed, inspected and finally disinfected with $2 \%$ glutaraldehyde solution. Master casts were poured (Fig. 2C). The cast was placed on a surveyor for examination and design of the cast metal framework (Fig.2D). It was then sent to laboratory for fabrication of metal framework. The occlusion rims were fabricated after checking the fit of the framework in the cast. The cast metal framework with occlusion rims was tried intra-orally for accuracy of fit (Fig. 3A).
Border molding was carried out in the usual fashion for the desired extension with green stick compound and secondary impression was made with zinc oxide eugenol paste (Fig. 3B), the fit of the metal framework to the teeth and soft tissues was checked during border moulding and secondary impression. After that the cast was altered in the laboratory. Two saw cuts were made perpendicular to each other in master cast (Fig. 4A).

The first cut was made $0.5 \mathrm{~mm}$ to $1.0 \mathrm{~mm}$ distal to the most distal tooth and perpendicular to the edentulous ridge. This cut was carried from the outer edge of the cast to 6.0 to $7.0 \mathrm{~mm}$ medial to the lingual vestibule.

The second cut was made parallel and medial to the edentulous ridge, extending from the most posterior aspect of the cast to the most medial aspect of the first cut.

In the cut surface of the cast, grooves were placed to aid in the retention of the newly poured stone. Complete seating of the framework on the cast was ensured before it was fixed in place with sticky wax. The final impression was beaded and boxed (Fig.4B) and the cast was poured with dental stone. Finally altered master cast was obtained (Fig.4C) and checked for metal framework in altered master cast (Fig. 4D). Bite registration, articulation (Fig. 5), try in and denture fabrication were carried out in usual manner. Denture was delivered to the patient (Fig.6) and post-operative instructions were given. The patient was satisfied with the outcome of the treatment. She was recalled for follow up after a day, 1 week, 1 month and 6 months. The final prosthesis was functioning satisfactorily. 


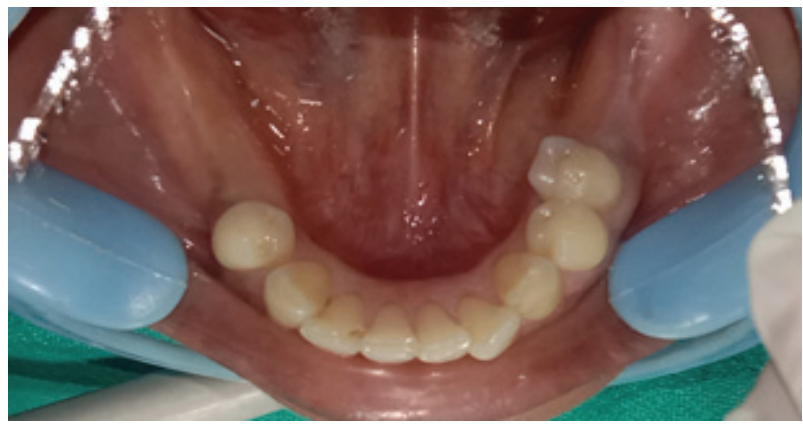

Figure 1: Intra oral view

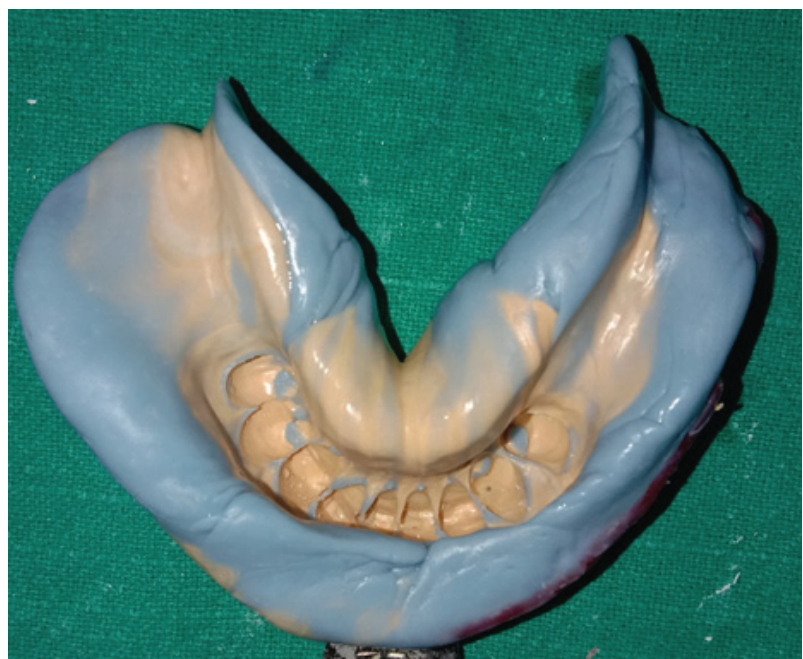

Figure 2B: Impression after mouth preparation

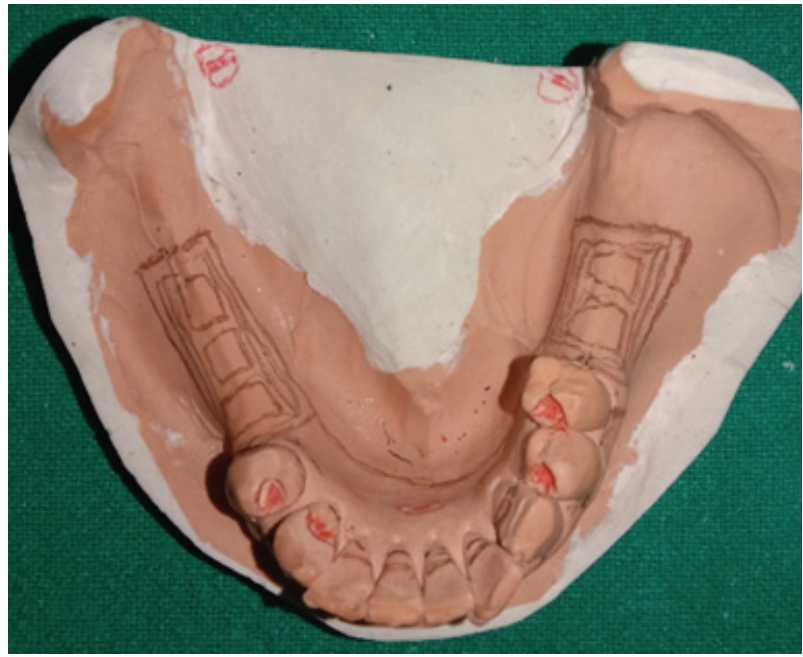

Figure 2D: RPD designing in master cast

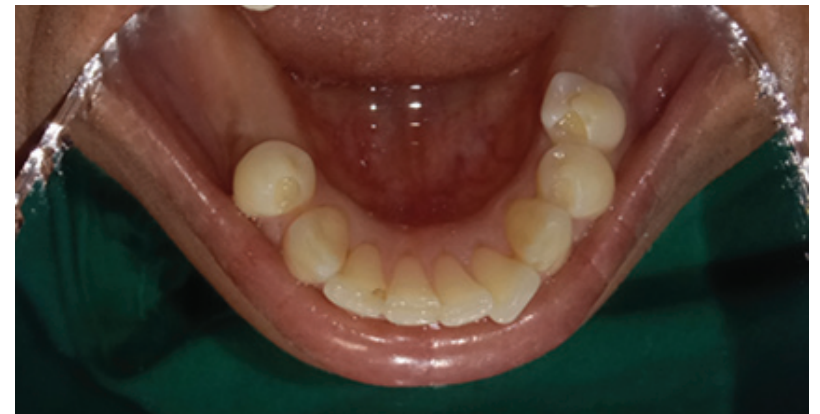

Figure 2A: Intra oral view after mouth preparation

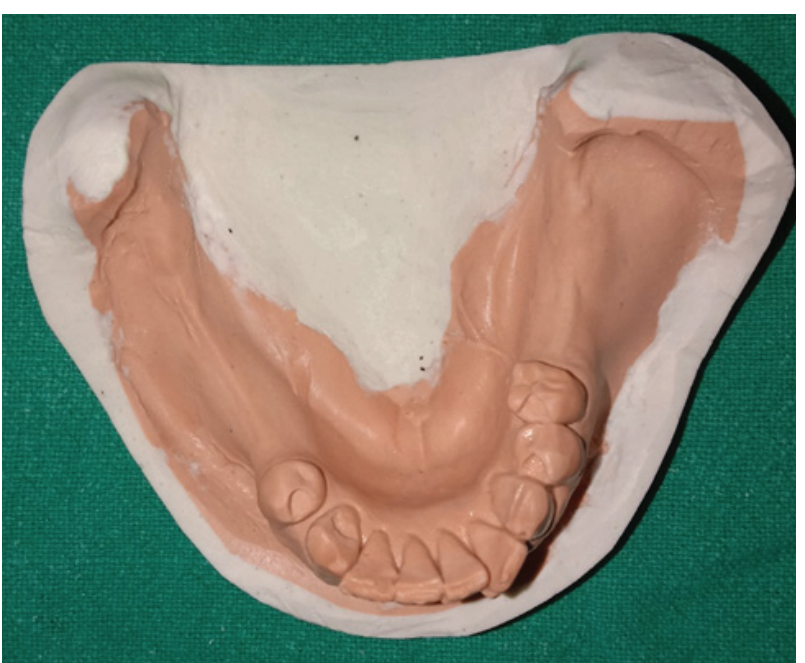

Figure 2C: Master cast after mouth preparation

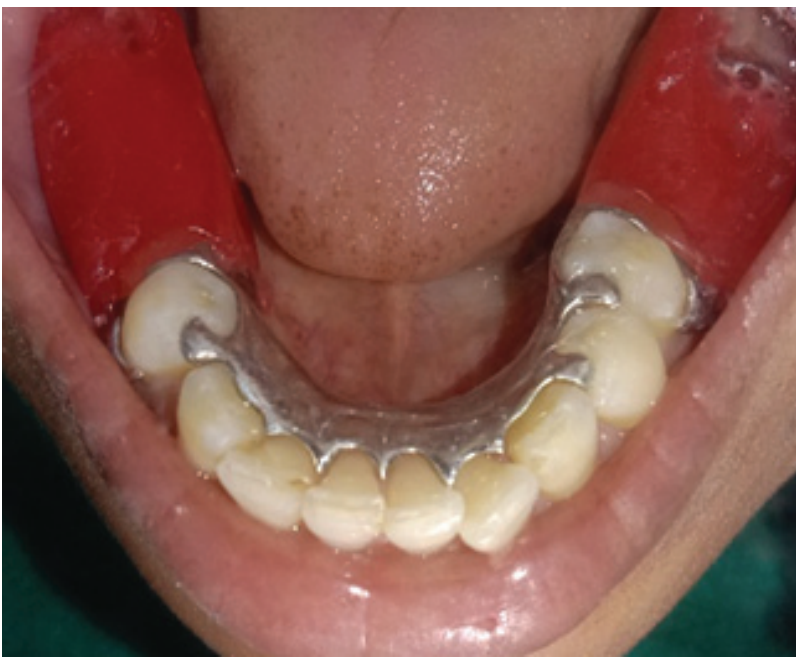

Figure 3A: Metal framework with occlusion rim checked intra orally 


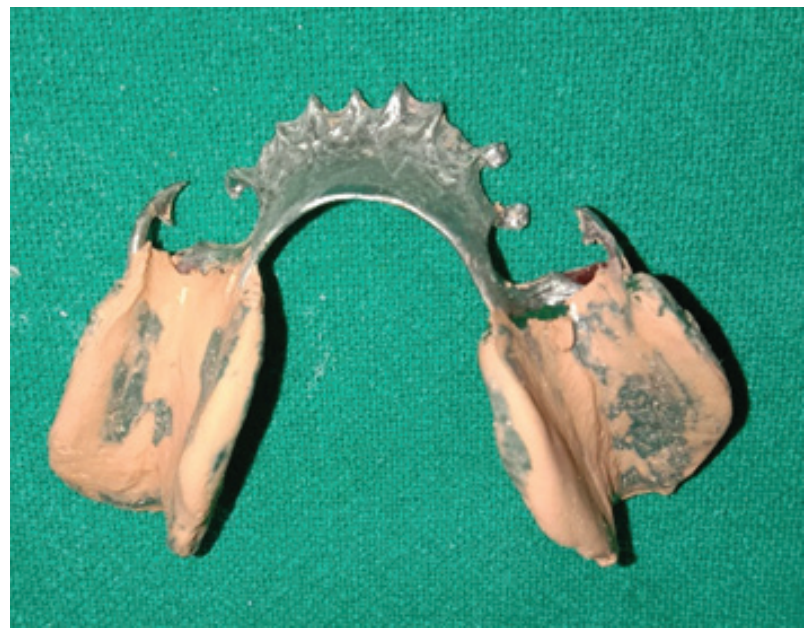

Figure 3B: Final impression with zinc oxide eugenol paste

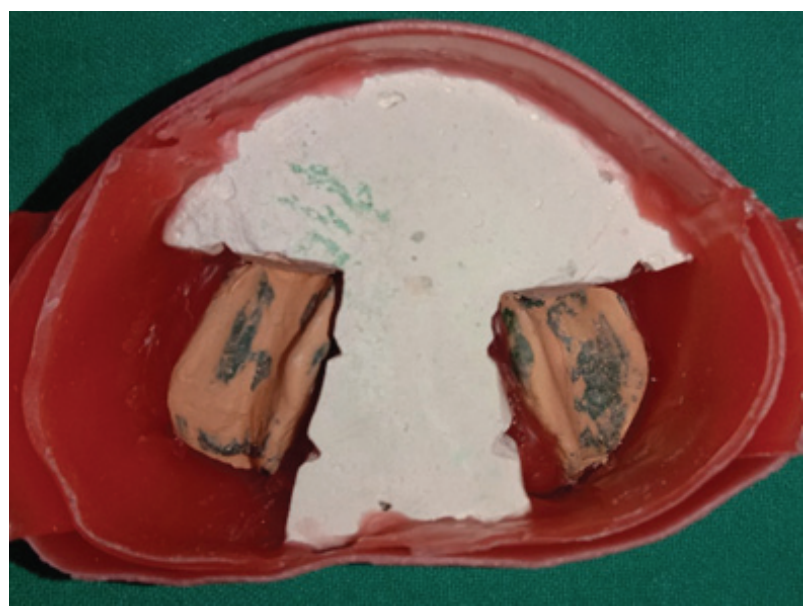

Figure 4B: Beading and boxing done

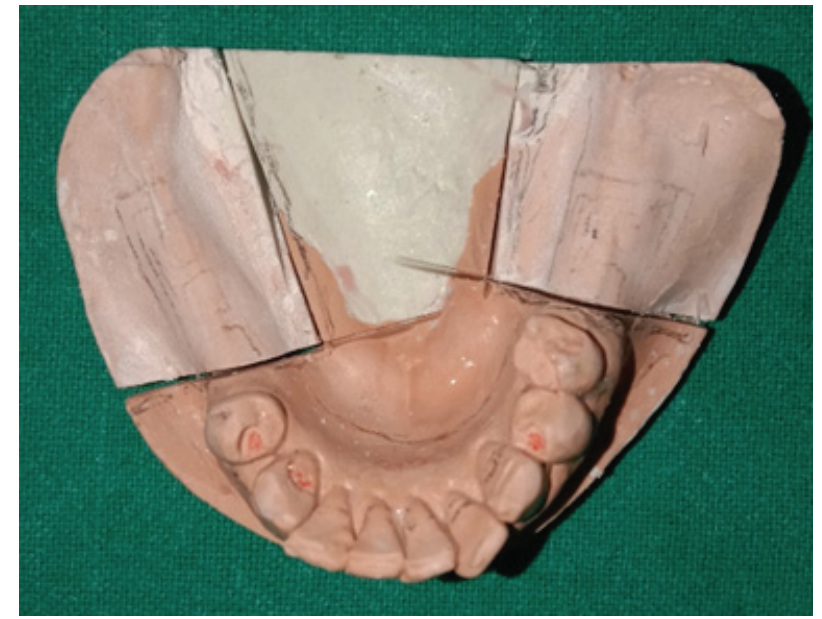

Figure 4A: Casts with two saw cuts perpendicular to each other

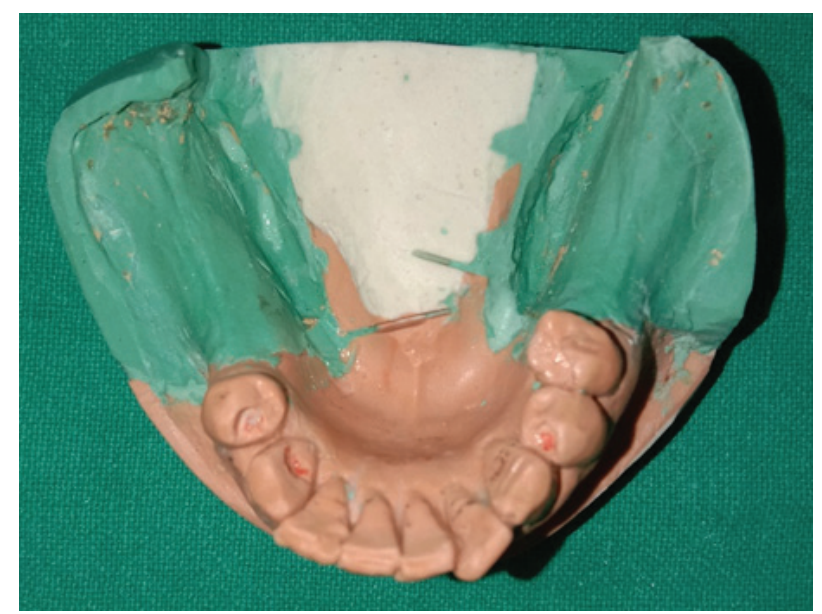

Figure 4C: Corrected cast obtained

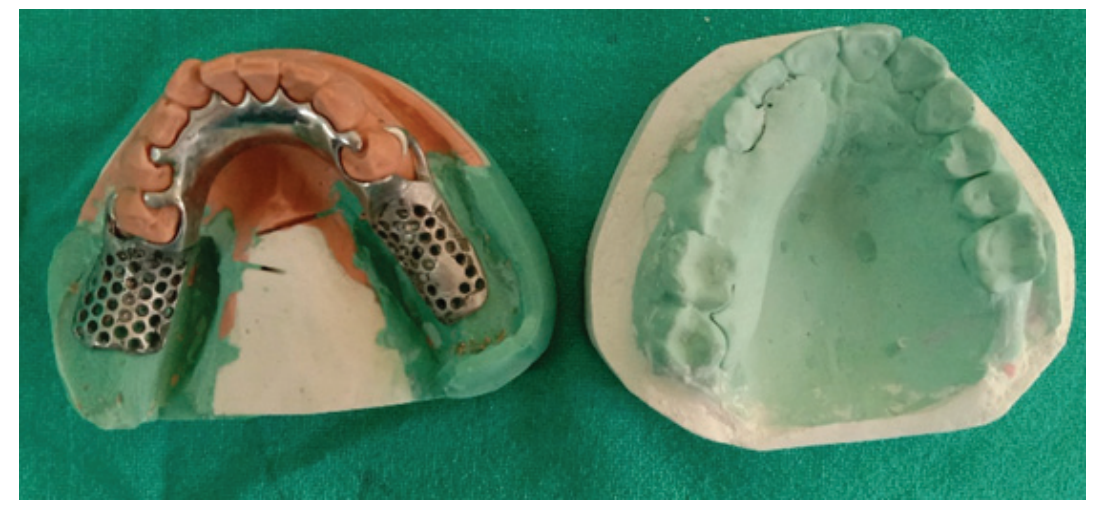

Figure 4D: Corrected cast with metal framework 

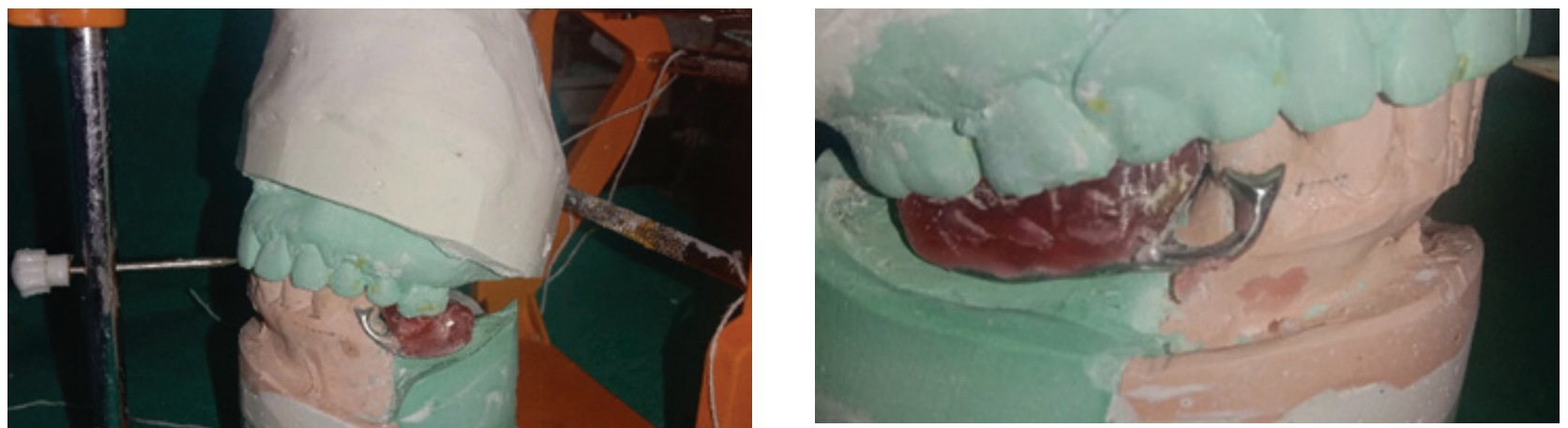

Figure 5: Articulation (Right and Left view)

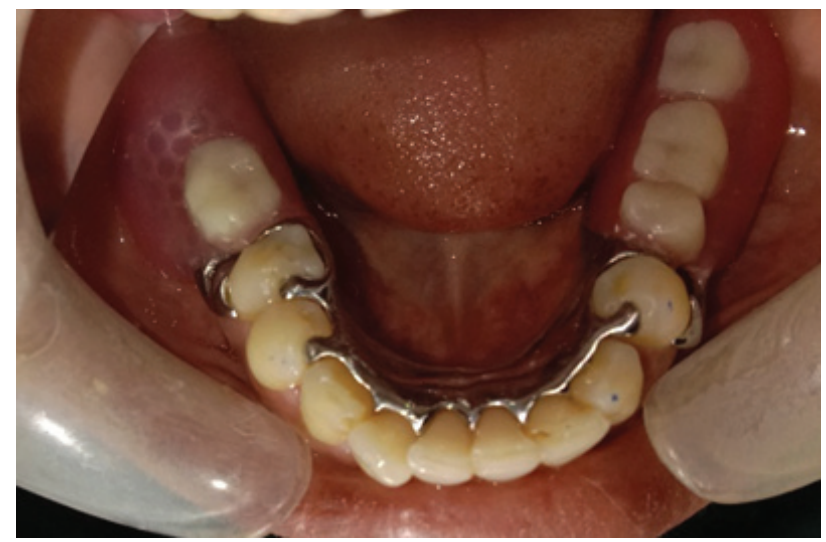

Figure 6: Final prosthesis in situ

\section{Discussion}

The Altered cast impression technique is commonly used for the mandibular distal extension partially edentulous arches (Kennedy's Class I and Class II). This technique is not commonly used in maxillary arches because of the nature of the masticatory mucosa and the form of tissue support. ${ }^{8}$ Since retention and stability has inherent problem of the distal extension removable partial denture and displaceability of the mucosa of the free end saddle are displaced under occlusal pressure, these problems can be overcome by altered cast technique. ${ }^{2,9}$ Applegate described original concepts of the altered cast technique. ${ }^{10}$ It is also known as the corrected-cast technique. ${ }^{11}$ It successfully fulfils the requirements of relating the anatomic form of teeth to the functional form of the residual ridge by simultaneously recording the surface contour and the ridge under masticatory function. ${ }^{12}$ Advantages of this technique include tissue support from minimally displaced soft tissue during impression making, improved support of distal extension partial denture, more predictable occlusion, maximum stability and minimum stress on abutment teeth. ${ }^{5,8,13}$ Other benefits of this technique are preservation of the residual ridges, decreased food impaction and reduced number of postoperative visits. ${ }^{7}$ Leupold $^{14}$ and Holmes ${ }^{15}$ said that the altered cast impression technique demonstrated the least amount of movement of the base at the time of placement and the most favourable ridge-to-denture-base relationship. According to the sixth principle of RPD design, altered cast procedure reduces the movement of the distal extension RPD, at least initially. ${ }^{16}$

In this clinical report, altered cast technique was chosen because this technique establishes length and thickness of extension of denture base, 
gives more accurate, functional impression of the supporting edentulous ridge. So, increased denture stability, preservation of the residual ridges, decreased the food impaction, minimal stress on abutment teeth, and more predictable occlusion can be obtained. The RPD fabricated with altered cast technique displayed less vertical movement of denture bases compared to those fabricated using conventional impression. ${ }^{17} \mathrm{~A}$ welldesigned removable partial denture with altered cast technique can be an excellent treatment alternative to implants and fixed prosthesis.

\section{Conclusion}

Partially edentulous Kennedy's class I and class II conditions has a good treatment plan of removable partial denture. The altered cast technique is simple and requires less chairside time and laboratory cost compared to implant supported prosthesis. Using altered cast technique, properly extended denture base stimulates underlying bone, distributes force uniformly and derives support from the teeth and the denture base.

\section{References}

1. Paul MJV, Mohan J, Kalaignan P, Simon P, Jai S. Altered cast impression technique for removable partial denture. J I Dent. 2017;2(3):1-5.

2. Khan MAA, Begum A, Hasan MN, Mohsina N, Jahangir MMR. Cast removable partial denture improving appearance and masticatory function - A case report.Updat Dent Coll J. 2013;1(1):1417.

3. Patel B, Shah S, Sethuraman R, Chhabra T, Gupta K. Rehabilitation of long span partially edentulous arch using clasp less cast partial denture and precision attachment - An aesthetic approach : Case Series.IOSR Journal of Dental and Medical Sciences. 2019;18(1):77-85.

4. Lil W, Solar P. Indications, diagnosis, and recall. In: Watzek G, editor. Endosseous implants: scientific and clinical aspects. Chicago: Quintessence; 1996. P.153-182.

5. $\mathrm{Ku} \mathrm{YC}$, Shen YF, Chan CP. Extracoronal resilient attachments in distal-extension removable partial dentures. Quintessence Int. 2000;31(5):311-317.

6. Prasad S, Monaco Jr EA. A modified treatment approach for fabricating a mandibular distalextension partial denture: A clinical report. Quintessence International. 2010;41(3):185189.

7. Sajjan C. An altered cast procedure to improve tissue support for removable partial denture. Contemp Clin Dent. 2010;1(2):103-106.

8. Rashid H, Vohra FA, Shahzad A. Altered cast technique: Improving tissuesupport for the distal extension bases. J Pak Dent Assoc. 2013;22(4):234-236.

9. Rajguru VL, Dange SP, Dahiwale DSS, Tandle UE. Altered cast impression technique. Int $\mathrm{J}$ of current Research. 2016;8(12):43095-43096.

10. Applegate OC. The cast saddle partial denture. J Am Dent Assoc. 1937;24(8):1280-1291.

11. Garcia EE, Evans JG. Removable partial dentures: The altered cast technique. J Dent Technol. 1998;15(7):25-29.

12. Li QL, Cao Y. A novel functional impression procedure for distal-extension removable partial dentures. International journal of dentistry and oral science. 2015;2 (11):168-172.

13. Frank RP, Brudvik JS, Noonan CJ. Clinical outcome of the altered cast impression procedure compared with use of a one piece cast. J Prosthet Dent. 2004;919(5):468-476.

14. Leupold RJ. A comparative study of impression procedures for distal extension removable partial dentures. J Prothet Dent. 1966;16(4):708-720.

15. Holmes JB. Influence of impression procedures and occlusal loading on partial denture movement. J prosthet Dent. 1965;15(3):474483.

16. .Becker CM, Kaiser DA, Goldfogel MH. Evolution of removable partial denture design. J Prosthodont 1994;3(3):158166.

17. Sayed M, Jain S. Comparison between altered cast impression and conventional singleimpression techniques for distal extension removable dental prostheses: A Systematic Review. Int J Prosthodont. 2019;32(3):265-271. 